\title{
建議与 批評
}

\section{对解决我国鍺工業原料問題的几点建竧}

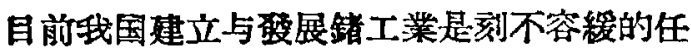
务。两完成这个任务，首先就应該解决銿的原料 来源問題。

踖是一个既稀有文疏散的宇素，因此原料問 題比較严重。目海对解决我国等工菜原料间題大 家有很多見解, 存在一些不同的看法。我想在这 个問題上是值得討諭的。

踷的克拉克值据最近的数据为 $7 \times 10^{-4}$ 。已

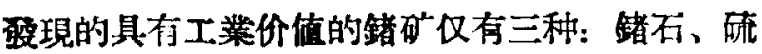
銀锗矿和硫銅锗矿。这三种鍺矿柾端稀有，抹且 集中程度很低，甚至談不上箖中。因此很多尃家 都認为独立的鍺矿牛不是重要的制鍺原料。目前 世界各国鍺工業以野矿为原料的占比重很小。一 般說来，偣祁是以副产物的形式得到的。因此，

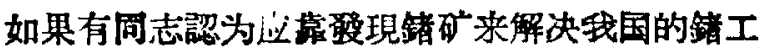
策的原料問題，歌是不妥当的。

缽的主姴原料来源应該从煤系統 和硫 化醇

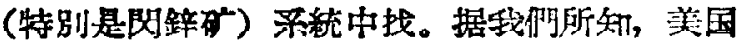
和比利时主夏从冶洯中回收鍺，英国和日本主 要从媒烟灰中提鍺，苏联主要从枯焦副产物中提 锗。

喰到煤中的错，应硋指出，早在1928-1983 年間著名的德国地球化学家戈尔德什米特 (V.M. Goldschmidt) 就群細地研究了煤中存在的 绪. 1937年莫尔崗 (G. T. Morgan) 和戴維斯 (G.R. Davies) 第一次婈了从煤气嘘烟灰中 提鍺的报告。到目前为止，世界各国有关蝶中鍺 的地球化学的論文, 估計已达百篇以上。

枼中鍺富集的原因至今扭沒有研究得十分洞 楚, 境法也很多; 不过一般認为是由于煤在形成 过程中植物分解所产生的窝植酸膵体吸附鍺的䋨 果, 而与煤中的矿物成分無关。研究証明, 白珐

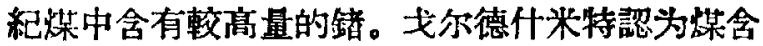

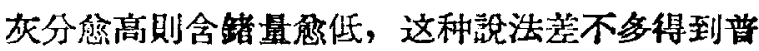
掘的証实。

苏联在三十年代就开始矿究媒中的鍺，采統 地研究锗的资源問題是由茎苏矿物 原料研究所 (BHMC) 完成的。苏联不同类型的然中会锗量为 0.001-0.01\%。煤灰中念斜量可高达1.0-1.1\%。

英国在 1950 年开始从烟灰中提锗的工棒生 产。英国煤中平均含鐯 $0.002-0.003 \%$ ，用以䗲 绪的喍烟灰中会鍺最高可到 $1.24 \%$ ，一般也能到 $0.62 \%$ 。根据計算，苂国每年媒产为一亿旽，可 以提鍺 2,000 吨。

日本在战后也开始来統地研究谋中的錯和踷 的地球化学。在印度交献中也有媒气蝟灰和媒灰 中含鍺量的报告。澳大利亞也是在 1938 年就有 蝶中赭的詳細报告。其他国家也有很㐱报告, 这 里不再列举。

媒中合哮量如为 $0.01 \%$ ，那就是地壳中含错 量的15倍。在煤的加工过程中（䗲焦、制造媒气 等)，锗矢有很高程度的漫縮。假如烟灰中含鍺 为 $1.0 \%$ ，那就是地壳中含铛 $1,500-2,000$ 倍。显然，含鍺量高的煤加工副产物就是很好的 工業原料。即便我国技术水平㜞低，一般含 $\mathrm{GeO}_{2}$ 到 $0.3 \%$ 也就可以考虑回收。所以，这是得决原 料問題的方向之一。

至于說到硫化矿中的錯, 那么閃鋅矿首先应 辟引起我們的注意。

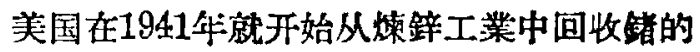
4工業生产。美国哈德棌周鋅矿含鍺达 $0.1 \%$,該 矿山的研水的固体沉腚物中会踷达 $0.29 \%$ 。美国 某些閃鋅矿㛐成的粗塊或氧化锌中含鍺在 $0.25 \%$ 以上。 
苏联也早在三十年代就开始研究硫化矿（其 中特別是閃鋅的)中的鍺。閶鋅矿中合鍺量变动范 圆很大，悓矿怵类型不同䦃含量在0.0005- - 0.1\% 之間。低温閃鋅矿中含鍺量較高, 平均可达 0.01 一 $0.1 \%$ 。械維鋅的含鍺量可高达 $0.3 \%$ 。

日本学者䁌經詳細地研究过鍺在硫化矿冶煉 过程中的行为。印度学者报告尼泊尔開鋅磁性 部分含鍺离达 $0.24 \%$ 。

在硫化矿加工和冶䍒这程中觰有一定程度的 富策。以锌治煉为例，有下列“地点”是鍺浱縮之 处:（一)鋅精研氧化焙燒过程中，鍺成为可揮登 的 $\mathrm{GeO}$ 逸出，而后及氧化成 $\mathrm{GeO}_{2}$ 存在于喍

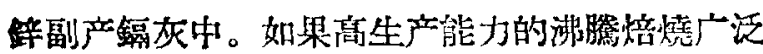
推广后，回收鍺就会更容易，鍺的回收等世高。

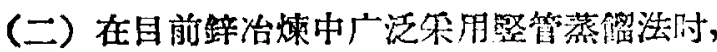
锗就留在殘渣中，含量可达 $0.1-0.5 \%$ 。（三）另

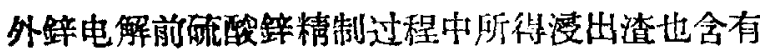
错。从嵙鋅生产过程中回收鍺是十分合理和必要 的。因为硫酸鋅溶液含微量鍺（例如每朴含 1 毫 克）就对鋅电解起着不良的影响，所以提鍺是一 誉㸚得。

除了锌的硫化矿以外，其他如錫矿、銀矿、

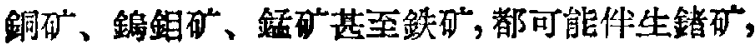
在一定条件下地能組織回收工作。近年来研究成 功的锗矿的浮选分离法，使得从各种多金疰矿中 回收鉻更加可能和有利。尔用浮选法以后，也不

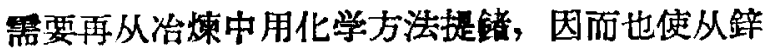
西中提鍺的工作简單化了。

根据以上所进，我們認为可以提出下列儿点 建議作为解决试国鍺工業原料問題的参考:

1. 中国科学院地質研究所应該渞手呼究鍺的 地球化学（就世界范圆来說，鍺的地球化学种不 是成熟了的），以便从理論上指导鍺資源的地筫調 查和生产調查工作。

2. 中国科学院、地質部、煤炭工業部、冶金 工業部鐝鉄工業管理局等，应該系統地研究我国 各主要媒田中的銤的分布情况，肚且柔統地研究 䦃在煤的加工过程中（选煤、燌焦、煤气生产
等) 的行为。必要时可用示踪原子方法（利用放 射性同位素 $\mathrm{Ge}^{77}$ )。

3. 在我国煤气生产抹不兴达的情况下，不能 硬搬英国等外国的經㗨，指望用烟灰来解決原料 来源問題。我們目前的烟灰数量不足以㴖足鍺生 产量的要求, 更好的办法是从三大鋼鉄基地的煤 焦厂中找出路。

4. 煤炭工業部应該研究更好的选煤方法以利 锗的回收。这方面, 苏联已經研觉成功, 我們可 以吸取苏联的經驗。

5. 科学院、地筫部、冶金工業部、化学工業 部等，应訪柔統地䃑究我国硫化矿（特别是閃鋅 矿以及我国富有的鵭、錫、䣄矿）中鉛的含量， 抹旦柔統地研究镜在硫化矿加工过程中(选矿、冶 整、硫酸生产) 的行为。必要时可以利用 $\mathrm{Ge}^{77}$ 。 6. 对硫化碎棌統中回收鍺来說, 我們認为最 好的方法是在选矿过程中用浮游选的“分出出錯磕 作为制鍺的原料。

7. 治金工業应該在加强原料綜合利用、全面 回收有价值金屬的工作中特别注意破究在选矿或 治煉过程中回收鍺的可能性。鍺容是被人忽略，

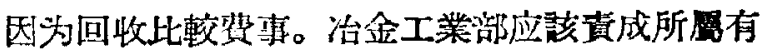
关厂矿加强这方面的工作。

8. 在我国鍺資源少未琴清之前，可以选摆有

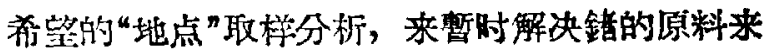
源問題。

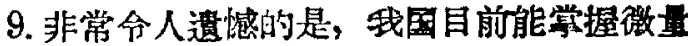
鍺的分析工作人員不多。这方面的問題可以用短

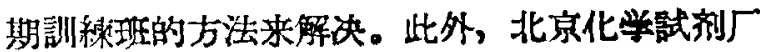
应該加速比色測定鍺用的有机呞剂的試制工作， 手且要大批生产。

10. 最后必須指出，目前我国关于錯的中文文 献很少，希望各有关部門加强有关鍺工業的書籍 的翻譯出版工作。就当放情况来馀，出版一本关 于鉝的地球化学和一本关于镜治煉的論文集是必 要的。

鲁 湘 